\title{
Prevalence of Depression Among Post-Graduate Medical Trainees: A Multi-Centre Survey
}

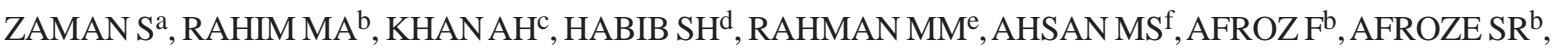 \\ HAQUE HF ${ }^{\mathrm{b}}$, AHMED JU ${ }^{\mathrm{b}}$, AHMED AKMS ${ }^{\mathrm{b}}$, HOSSAIN MD ${ }^{\mathrm{b}}$, RAHMAN MR ${ }^{\mathrm{b}}$, MUSAAKM ${ }^{\mathrm{b}}$, UDDIN KN ${ }^{\mathrm{b}}$
}

\begin{abstract}
Objectives: To describe the prevalence of depression among post-graduate medical students and to evaluate some related risk factors.

Methodology: This cross-sectional survey was done in three post-graduate medical teaching institutes in Dhaka, Bangladesh in February 2013. A preformed questionnaire including some demographic, socio-economic and work related variables was used for the purpose and depression was diagnosed and severity assessed by using Hamilton Rating Scale for Depression (HAM-D).

Results: A total of 100 post-graduate medical trainees were given a preformed questionnaire. Among them 53 students filled it up properly and sent back in given time (response rate was 53\%). Mean age of the respondents was 31.6 years,
\end{abstract}

\section{Introduction}

Depression is common, being one of the three most common causes of morbidity worldwide and anticipated to be the commonest cause by the year $2030 .{ }^{1}$ Globally over 150 million people are suffering from depression. ${ }^{1}$

a. Dr. Shahana Zaman, FCPS (Cardiology), Registrar, Department of Cardiology, NICVD, Dhaka, Bangladesh.

b. Dr. Muhammad Abdur Rahim, FCPS (Medicine), Registrar, Dr.Farhana Afroz, FCPS (Medicine), Dr. Samira Rahat Afroz FCPS (Medicine), SMO, Dr. Hasna Fahmima Haque, FCPS (Medicine), Registrar, Dr. Jamal Uddin Ahmed, FCPS (Medicine), Asst. Prof, Dr. AKM shaheen Ahmed, FCPS (Medicine), Dr. Md. DelwarHossain, MD (Chest), Dr. Md. RaziurRahman, MD (Medicine), Asso. Professor, Prof. AKM Musa, FCPS (Medicine) and Prof. Khwaja NazimUddin' FCPS (Medicine), Head, Department of Internal Medicine, BIRDEM, Dhaka, Bangladesh.

c. Dr. Md. Abed Hussain Khan, FCPS (Medicine), MO, Medicine Department, BSMMU, Dhaka, Bangladesh.

d. Samira Humaira Habib, M Phil, Senior Research Officer, BADAS, Dhaka, Bangladesh.

e. Dr. Md. Mahbubur Rahman, MD (Gastro), SMO,Dept. of GHPD, BIRDEM, Dhaka, Bangladesh.

f. Dr. Md. Shamsul Ahsan, FCPS (Psy), Asst. Prof, Dept. of Psychiatry, BSMMU, Dhaka, Bangladesh.

Corresponding author:Dr. Shahana Zaman, FCPS (Cardiology),Registrar, Department of Cardiology,NICVD, Dhaka, Bangladesh, e-mail: muradrahim23@yahoo.com, banee2003@yahoo.com.

Received: April 15, 2013 Accepted: December 31, 2013 male and females were almost equally distributed. Depression was present in 21 (39.6\%) respondents. Among them 17 (80.9\%) had mild depression and 4 (19.1\%) had moderate depression. None of the respondents had severe or very severe depression. Increased age, low income, marital status, living away from family, smoking, long working hours and inadequate time for study appeared as important risk factors.

Conclusion: Two-fifth of post-graduate medical trainees suffered from mild to moderate depression. This issue should be properly addressed because of its possible impact on training outcome.

Key words: depression, post-graduate students/ trainees, prevalence, risk factors.

(Birdem Med J 2014; 4(1): 18-21)

The lifetime risk for development of depression is 7$12 \%$ for men and $20-25 \%$ for women worldwide; these rates are independent of race, education, earnings or social status. ${ }^{2}$ The estimated prevalence of depression in Bangladesh is 3-4\% and the life-time prevalence of major depressive disorder is $4.6 \%{ }^{3,4}$

Doctors are not different from the community, rather postgraduate medical trainees have stressful life because of their training, long working hours, frequent dealing with severely ill patients, study to keep up to date and examinations,though some doubt remains whether it differs in that respect from other higher educations. ${ }^{5,6}$ One-fourth to one-third of the post-graduate medical trainees and residents develop clinical depression at some point in their training period although much higher rates were reported in some other studies. ${ }^{7-9,5}$

Unfortunately, we do not have any statistics regarding depression among our post-graduate medical students and trainees. In this study, we have tried to evaluate the prevalence of depression among post-graduate medical trainees and also tried to evaluate some demographic, socio-economic and work-related factors as possible risk factors for development of depression. 


\section{Methods}

This cross-sectional survey was done in February 2013. Respondents were from Bangladesh Institute of Research and Rehabilitation in Diabetes, Endocrine and Metabolic Disorders (BIRDEM), Bangabandhu Sheikh Mujib Medical University (BSMMU) and Dhaka Medical College Hospital (DMCH), three reputed post-graduate medical teaching institutes in Dhaka, Bangladesh. Postgraduate medical trainees in Medicine and related subspecialities, who have enrolled themselves into a definite post-graduate course for example Fellowship of Bangladesh College of Physicians and Surgeons (FCPS), Doctor of Medicine (MD), Membership of Royal College of Physicians (MRCP) or Diploma were included in this study. Those trainees who have completed training and appeared in examinations either passed or failed and those who were doing training but not enrolled into a definite course were excluded. A preformed questionnaire including some demographic, socioeconomic and work-related factors was used for the purpose. Depression was diagnosed and severity assessed by using Hamilton Rating Scale for Depression (HAM-D). SPSS version 11.0 was used to analyze data. Independent sample t-test was used to observe the significant value (p value) at 5\% level.

\section{Results}

A total of 100 post-graduate medical trainees were given the questionnaire by person to person contact or by e- mail. Among them 53 students filled up the form properly and sent it back within a given time. So, the response rate in this survey was 53\%, with slight female predominance (total 53, female 27, male 26). Most (51, $96.23 \%)$ were married and two-third (66.67\%) were parents. Over two-third (38, 71.7\%) live with family and rest singly and away from family. Mean age of the respondents was 31.6 years.

Half (26, 49.1\%) of the respondents were from BIRDEM, over one-third (19, 35.8\%) were from BSMMU and rest $(8,15.1 \%)$ were from DMCH. Majority $(38,71.7 \%)$ were doing training for medicine and rest for other subspecialities. Over half $(29,54.7 \%)$ of the respondents were in their $4^{\text {th }}$ year of training. Almost all the respondents had very good supervisor's (52, 98.11\%) and colleagues' (51, 96.23\%) support. None of the respondents were abusing alcohol or any recreational drugs. Nobody suffered from psychiatric illness in the past and none had such family history.

Depression was present in 21 (39.6\%) of the respondents and these were mild $(17,80.9 \%)$ to moderate $(4,19.1 \%)$ and none of the respondents had severe or very severe depression. Depression was more common among married, male trainees who used to live away from family and who do not get adequate colleague's support (Table I and II). Long working hours, low monthly income and smoking habit appeared as significant risk factors for depression (Table II).

Table I

\begin{tabular}{lcccc}
\multicolumn{5}{c}{ Some socio-demographic risk factors for depression } \\
Variables & $\mathrm{N}(\%)$ & Depression present (\%) & Depression absent (\%) & Odds ratio \\
\hline Age & & & \\
$<30$ years & $11(20.75)$ & $2(18.18)$ & $9(81.82)$ \\
$30-35$ years & $28(52.83)$ & $13(46.43)$ & $15(53.53)$ & $8(57.14)$ \\
$>35$ years & $14(26.42)$ & $6(42.86)$ & 1.95 \\
Sex & & & $13(50)$ \\
Male & $26(49.06)$ & $13(50)$ & $19(70.37)$ \\
Female & $27(50.94)$ & $8(29.63)$ & \\
Marital status & & & $30(58.82)$ \\
Married & $51(96.23)$ & $21(41.18)$ & $2(100)$ \\
Unmarried & $2(3.77)$ & $0(0)$ & & 2.38 \\
Having children & $51(100)$ & $15(44.12)$ & $19(55.88)$ \\
Yes & $34(66.67)$ & $6(35.29)$ & $11(64.71)$ \\
No & $17(33.33)$ & $11(73.33)$ & & \\
Living away from family & & $10(26.32)$ & $4(26.67)$ \\
Yes & $15(28.30)$ & & $28(73.68)$ \\
No & $38(71.70)$ & &
\end{tabular}


Table II

\begin{tabular}{|c|c|c|c|c|}
\hline \multicolumn{5}{|c|}{ Work-related and personal risk factors for depression } \\
\hline Variables & $\mathrm{N}(\%)$ & Depression present (\%) & Depression absent (\%) & p-value \\
\hline \multicolumn{5}{|c|}{ Working hours/ week } \\
\hline$<48$ hours & $6(11.32)$ & $0(0)$ & $6(100)$ & \\
\hline 48-72 hours & $41(77.36)$ & $16(39.02)$ & $25(60.98)$ & 0.001 \\
\hline$>72$ hours & $6(11.32)$ & $5(83.33)$ & $1(16.67)$ & \\
\hline \multicolumn{5}{|l|}{ Monthly income } \\
\hline$<10,000$ taka & $6(11.32)$ & $5(83.83)$ & $1(16.67)$ & \\
\hline 10,000-20,000 taka & $36(67.92)$ & $14(38.89)$ & $22(61.11)$ & 0.003 \\
\hline$>20,000$ taka & $11(20.75)$ & $2(18.18)$ & $9(81.82)$ & \\
\hline \multicolumn{5}{|c|}{ Enough time for study } \\
\hline Yes & $42(79.25)$ & $10(23.81)$ & $32(76.19)$ & 0.524 \\
\hline No & $11(20.75)$ & 11(100) & $0(0)$ & \\
\hline \multicolumn{5}{|l|}{ Colleagues' support } \\
\hline Yes & $51(96.23)$ & $19(37.25)$ & $32(62.75)$ & \\
\hline No & $2(3.77)$ & $2(100)$ & $0(0)$ & \\
\hline \multicolumn{5}{|c|}{ Supervisor’s support } \\
\hline Yes & $52(98.11)$ & $21(40.38)$ & $31(59.62)$ & \\
\hline No & $1(1.89)$ & $0(0)$ & $1(100)$ & \\
\hline \multicolumn{5}{|l|}{ Smoking habit } \\
\hline Yes & $19(35.85)$ & $15(78.95)$ & $4(21.05)$ & 0.001 \\
\hline No & $34(64.16)$ & $6(17.65)$ & $28(82.35)$ & \\
\hline
\end{tabular}

\section{Discussion}

This study was designed to evaluate the prevalence of depression among post-graduate medical students and to evaluate some demographic and socio-economic and work-related factors as possible contributory factors. Response rate was 53\% which was lower than similar other studies among post-graduate and under-graduate medical students. ${ }^{5,10,11}$

In this current study, nearly $40 \%$ of the respondents had depression, which is much lower than a similar study done by Yousuf A et al ${ }^{5}$ but three times more frequent than another study done in the United States. ${ }^{9}$ In the former study, the authors claimed that the survey period was near the ending of an academic year, which might have important contributory role. In similar survey done among under-graduate medical students including intern doctors in India, depression was present in $27.08 \%$ cases, mostly mild to moderate depression ${ }^{10}$, it was nearly $30 \%$ in Turkey ${ }^{12}$ while in the United Kingdom these rates were $10-18 \% .{ }^{13}$ Among the Chinese University students, depression was a prevalent condition accounting major depressive disorders in $4 \%$ cases. $^{14}$

According to World Health Organization, risk factors for depression in general population are females, separated or divorced, family history of depression, early parental loss, negative stressful events, chronic stress, lack of social support and living in urban areas. ${ }^{2}$ In our study, long working hours, low monthly income and smoking habit appeared as significant risk factors for depression. Besides these, married, male trainees who live away from family suffered from depression more frequently. One important reason might be that, due to our social context, husband has to take the responsibility of a family, so they are more stressed in a similar context 
than a female and suffered from depression more commonly. Yousuf A et al in their study found that age, religion, ethnicity, marital status, living status, speciality, colleagues' support, supervisor's support, enough time for academics and smoking were important risk factors for depression. ${ }^{5}$ In an Indian study, religion, family history of chronic illness, history of parental loss and unsuccessful love affairs appeared as important risk factors for depression among under-graduate medical students ${ }^{10}$ while substance abuse, family history of depression and anxiety and recent loss of a relative were important risk factors in Pakistan. ${ }^{11}$

\section{Limitation}

This study had some limitations. Limited number of students responded over a short period of time. There was institutional and sampling bias. Some other variables like recent life events and seasonal variation were not considered.

\section{Conclusion}

From this study, it can be concluded that, depression among post-graduate medical trainees is common and it is much more common than general population. It is unrecognized, under-estimated and not properly addressed. This issue should be properly addressed because of its possible impact on quality of health care services in teaching hospitals and on training outcome.

\section{References}

1. World Health Organization: The Global Burden of Disease: 2004 update. Available from URL:http://www.who.int/ (cited March 6, 2013)

2. World Health Organization: Mental Health and Substance Abuse Facts and Figures Conquering Depression update. Available from URL:http://www.searo.who.int/ en/ Section 1174/Section 1199/Section $1567 /$ Section 1826 8108.htm.

3. Karim ME, Firoz AHM, Alam MF. Assesment of Depression in Parkinson's Disease, Psoriasis, Stroke and Cancer Patients. Ban J of Psychiatry 2001;15:11-18.
4. Firoz AHM, Karim ME, Alam MF. Community Based Multi-centric Service Oriented Research on Mental Illness with Focus on Awareness, Prevalence, Care, Acceptance and Follow-up in Bangladesh. Manual on Mental Health for Primary Health Care Physicians.2 ${ }^{\text {nd }}$ edn. NIMH\&WHO, 2007.

5. Yousuf A, Ishaque S, Qudwai W. Depression and Its Associated Risk Factors in Medical and Surgical Postgraduate Trainees at A Teaching Hospital: A Crosssectional Survey From A Developing Country. JPMA 2011;61:968-72.

6. Firth-Cozens J. Medical Students Stress. Med Educ 2001;35:6-7.

7. Sadeghi M, Navidi M, Sadeghi AE. Depression among Resident Doctors in Tehran, Iran. Iran J Psychiatry 2007; 2:50-52.

8. Peterlini M, Tiberio IF, Saadeh A, Pereira JC, Martins MA. Anxiety and depression in the first year of medical residency training. Med Educ 2002;36: 66-72.

9. Katz ED, Sharp L, Ferguson E. Depression among emergency medicine residents over an academic year. AcadEmerg Med 2006; 13: 284-87.

10. Sahu PC, Inamdar IF, Obaidulla M, Tambe S, Gadeker RD, Sonkar VK, et al. Study of depression among medical students of different pathies in Nanded City, Maharashtra. J Evol Med Den Sci; Published online on $31^{\text {st }}$ March, 2013.

11. Khan MS, Mahmood S, Badshah A, Ali SU, Jamal Y. Prevalence of depression, anxiety and their associated factors among medical students in Karachi, Pakistan. JPMA 2006;56:583-86.

12. Karaoglu N, Seker M. Anxiety and depression in medical students related to desire for and expectations from a medical career. West Indian Med J 2010;59 (2):196-202.

13. Quince TA, Wood DF, Parkel RA, Benson J. Prevalence and persistence of depression among under-graduate medical students: a longitudinal study at one UK medical school. BMJ Open. 2012; 2(4): e001519. Published online on August 9, 2012. doi: 10.1136/bmjopen-2012-001519

14. Chen L, Wang L, Qiu XH, Yang XX, Qiao ZX, Yang YJ, et al. Depression among Chinese university students: prevalence and socio-demographic correlates. PLoS ONE 8(3): e58379. doi:10.1371/journal. Published online on March 13, 2013. 